\title{
Spatial-Temporal Pattern of Urban Growth in Tehran Megapole
}

\author{
Faranak Seifolddini ${ }^{1} \&$ Hossain Mansourian ${ }^{1}$ \\ ${ }^{1}$ Department of Geography and Urban Planning, University of Tehran, Tehran, Iran \\ Correspondence: Faranak Seifolddini, Department of Geography and Urban Planning, University of Tehran, Iran. \\ Tel: 98-09-122-973-829. E-mail: seifolddini_faranak@hotmail.com
}

\author{
Received: December 19, 2013 Accepted: January 6, 2014 Online Published: January 26, 2014 \\ doi:10.5539/jgg.v6n1p70 \\ URL: http://dx.doi.org/10.5539/jgg.v6n1p70
}

\begin{abstract}
Rapid urbanization and urban growth are complex problems in countries, such as Iran. The major goal of current research is to determine the spatial-temporal pattern of urban growth in Tehran megapole. This research can provide a background for more informed planning. Current research used historical maps and satellite images to determine the urban growth patterns for Tehran megapole for the time period 1921-2011. Spatial metrics were used to analyze the spatial-temporal pattern of urban growth at two levels: Tehran's Megapole as whole and within the concentric zones in this Megapole. Results show that urban growth rate in Tehran megapole area can be divided into three major periods: (1) rapid growth rate (1921-1976), (2) very rapid growth rate (1976-1986), (3) slow and consistent growth rate (1986-2011). Results also show that urban growth in Tehran city follow tidal waves pattern and consequent phases of growth. These tidal waves are moving toward external edges of Tehran city. This research was an attempt to apply a remote sensing methodology for urban planning purposes. Also, it was an attempt to determine the pattern of urban growth in Tehran megapole which was not determined before.
\end{abstract}

Keywords: urban growth, spatial metrics, diffusion, coalescence, urban DNA, Tehran megapole

\section{Introduction}

Since industrial revolution at the end of 18 th century, world urban population has increased exponentially with rapid speed. In 1830, urban population was about are 1 billion and it increased to 7 billion in 2011. Moreover, urban population increased more rapidly compared with rural population. Urban population increased from 14 percent in 1900 to 50.5 percent in 2010. It is predicted that by 2030, more than 60 percent of population are urban resident (Wu et al., 2010). United Nation has estimated that urban population in developing countries will increase from 2.048 billion in 2000 to 3.991 in 2030. It is expected that urban population in developed world increase from 870 million to 1.01 billion ( $\mathrm{Wu}, 2008$ ). Although the proportion of urban residents and urbanization are different between developing and developed world, the increase in urban population growth is a global trend.

Urban areas have occupied small proportion of the earth surface; but this small proportion of land occupation cannot be ignored because of its considerable impact on natural and human systems (Kong et al., 2010). Urban growth, especially in its undesirable form has negative impact on the environment, natural resources, human health and has caused some socio-economic problems. Decrease in agricultural lands, wild forests and open spaces are considered as some impacts. These changes have also had impacts on ecosystems, wild life, quality of water and air and consequently human health and quality of life. Spatial pattern of growth on urban areas are changing in a complex way. Urban areas are expanding in rural areas and urban sprawl is occurring. Because of continuous change in structure and pattern of urban growth, these areas have been in continuous focus of researchers (Seto \& Fragkias, 2005).

Characterizing and understanding the changing patterns of urban growth is critical, given that urbanization will continue to be one of the major global environmental changes in the foreseeable future. The physical Process of urban land use changes on a result of urbanization are under study and research (Seto \& Fragkias, 2005).

Although urbanization is a global event, this event is very dynamic in Iran. Considerable urban growth has occurred in the last few decades in Iran. During the past 55 years, the proportion of urbanization has increased from 31 percent in 1956 to more than 71 percent in 2011. During the past five decades, urbanization has been increasing in Iran similar to other third world countries. Urbanization has increased as a result of rural population migration, natural population increase and annexation of rural areas to urban areas. New urban growth pattern 
have emerged and megapolis and megapolitan areas have emerged.

Since 1950s, with the establishment of capitalist system in Iran, new stage occurred in urbanization and urban development in Iran, especially in Tehran. Rural land reforms were implemented in 1962, and consequently changes occurred in the relation between rural and urban areas. Rural population migrated to urban areas. Rapid increase in oil revenues, needs for urban services, developments in economic and communication infrastructure, rapid increase in establishing major industries and assembling industries, broad growth of administrative organizations increased the role and functions of Tehran city as the capital and as the center of new changes. Therefore, Tehran city was expanded and became more complex. In the years after revolution, urban sprawl and discontinuous expansion have been the dominant form of urban growth (Mehdizade, 2003).

The first step in the management, control and scientific intervention in Tehran megapole's growth is providing a comprehensive view about the spatial-temporal pattern and process of urban growth. On this basis, pattern of urban growth, analysis of spatial changes in time and causes of changes is necessary. Study of patterns of urban growth in many developed and developing countries, considering their socio-economic conditions, shows that management and scientific planning are needed as the basis of right understanding of the spatial-temporal processes of urban growth. Recent scientific progresses, such as remote sensing, GIS, other spatial techniques and progress in fields such as landscape ecology have helped to enable us to quantify, to do modeling and to predict urban growth (Kong et al., 2012).

Spatial metrics are useful tools for producing maps and quantifying the spatial characteristics of urban growth (Kong et al., 2012). On this basis, the major goal of this study is to show the spatial-temporal changes of Tehran's growth between 1921-2011, using spatial metrics.

\section{Literature Review}

To define urban growth, two indicators were used: (1) population growth, (2) physical growth. Urban population growth is defined as the absolute increase in urban population, and can be the indicator of population growth. Urban physical growth is defined as the increase in the absolute urban land area. Considering the physical growth indicator, urban growth can be measured in two ways: (1) changes in the distribution of internal density of land use within the city (2) increase in the urban land area in edges of the city. Theories such as urban rent theory, central place theory, concentric zone theory, sector theory and multiple nuclei theories have described and analyzed the dynamic nature of urban growth (Bourne, 1971).

Spatial-temporal studies of urban growth have been used in primary studies (1950-1970), mostly as the basis of demographic and socio economic studies. In this period, important studies and important questions were formed. One of these questions was about cities physical form in different time periods. One of the important theories, which answered this question, was the spatial-temporal theory of urban growth by Blumenfeld in 1954, who described the growth as tidal waves. Blumenfeld (1954) studied population changes in 15 concentric zones, extending 25 miles from city center in Philadelphia over a 50 year time period. First he found that for any given distance zone from the center of the metropolis, there is a similar type of tidal wave pattern. Each zone in succession rises relatively steeply to a peak, or crest, of density. Then declines more slowly and flattens out; probably to begin a new rise again. Second, he found that the amplitude of each wave decreases as one goes outward from the center of the city. The waves also crest much more steeply in the inner zones. Blumenfeld wrote that in any given time period, there is a particular "zone of maximum growth", which we may define as the crest of the tidal wave of metropolitan expansion. This crest moves slowly and fairly regularly outward from the center of the metropolis to its periphery (Bourne, 1971).

Blumenfeld theory was developed by researches such as Boyce (1969); Clark (1952); Korcelli (1976); Hoover and Vernon (1959); Cressy (1939); Duncan et al. (1962); Winsborough (1962). While the theoretical foundations of many of these early formulations vary in strength, the basic notion of urban cycles or phases is apparent in all of them. This idea has more recently been posed in a similar form by White et al. (2001) through their investigation of form as it relates to European land use processes, yet they do not fully expand on the concepts of phases, but do suggest some temporal component as being explanatory of form. White et al. (2001) were still left with many questions at the conclusion of their research, including: how spatial patterns of land use evolve through time; do they vary from city to city; and what do they tell about the system and underlying processes? Consequently this research is along similar lines, drawing on older geographic concepts as a basis, and again raising the question: do urban systems exhibit oscillatory behavior over time? Specifically, if such harmonics can be shown to exist, how can they be quantified and modeled (Dietzel et al., 2005)?

Patterns of urban growth are different in different cities; but there are global patterns and mechanisms (Wu et al., 2011). Urban growth is the result of endless waves of suburbanization at the cities' edges. Two 
macro-mechanisms work:

1) Urban DNA: is a concept referring to a city's characteristics such as topography, soil, economic, political, cultural and environmental characteristics. Hall wrote that every city has its own DNA which makes the city unique (Wu \& Silva, 2011).

2) Second mechanism is suburbanization moves that are the result of these events including: natural evolution, flight from blight and urban land value.

Natural evolution emphasize the population and life style changes such as changes in the level of income, family size and other characteristics that increase the demand for new and larger residential units in the suburbs and surrounding rural areas (Bayoh, 2002). Urban growth pattern follows the urban transition pattern. In phase one, urbanization, the highest level of growth occurs in the core. In the second phase, suburbanization occurs further from the core. In third phase "counter urbanization" occurs, when the population moves from core and suburbs to outer layers and surrounding rural areas. On the basis of this model, urban sprawl occurs in phase three. Mieszkowski et al. (1999) develop a theory called "flight from blight". This theory suggests that with the increase in the level of income, higher tax rates in inner sectors of the city, deterioration of the infrastructure, lower quality of life in the central parts of the cities, with the presence of more poor families and minorities, more dispersion happen. People try to avoid real and perceptual blight in central areas. The desire to live in the homogenous neighborhoods affects urban physical expansion.

Theory of urban land value suggests that since the decisions about use of land are on the basis economic criteria, more urban sprawl is observed (Ladda, 1998; Lewis, 2001). If there are no major limitations, concentric growth is the major form of urban physical expansion (Foreman, 2008), affected by mentioned mechanisms, concentric zones are developed. But concentric zones might be affected by urban DNA. The history of urban physical expansion can be explained on the basis of tidal waves. Dimension and direction of these waves depends on the external and internal factors. Within each zone, these phases are observed: Phase one: dispersed growth and mostly residential; Phase two: progressive density and added commercial and public services; Phase three: increase in density and in different land uses (Gandy \& Sylvie, 2002).

\section{Method}

Tehran city has passed different stages of development and evolution (Figure 1). In 1922, Tehran's population was 210,000 , with the average density of 85 individuals in each hectare, residing in the 10 regions. With demolishing the old wall surrounding the city, the population reached 310,000. Between 1932-1937, with the direct intervention of the government, the whole wall surrounding the city was destroyed and Tehran's land area was 46 square kilometer. The population reached 540.000 in 1939 and 600,000 in 1941. In 20 years, the population was tripled. With the socio-economic changes, considerable changes were occurred in ecology and geography of Tehran.

Traditional agricultural production system was replaced with industrial production and capitalist system. New social classes such as administrative employees, employees in army, labors and new unions were established. New commercial, service and cultural centers were developed out of bazaar. New industrial centers were established along roads around the city, providing the base and direction of future development. With the fall of Reza Shah (king) in 1941, changes in socio-economic conditions in Iran and city planning were governed by a centralized government. In 1953, with the support of United States of America, Reza Shah's son (second king) and capitalist system, investment in industrial sections were increased. New industrial areas were developed in west and southwest of Tehran. In 1962, land reform law was implemented and rural population migration to the cities occurred. With the increase in the level of oil income, rapid growth of economic infrastructure and communication system, increase in industrial production, assembling industry, rapid increase in the number of government and administrative organizations were occurred. Role and functions of Tehran as capital was increased. Tehran became the largest center for attracting population, capital, jobs, income and services. In 1960, many surrounding villages were annexed to the city. Suburban areas were expanded. Fast physical expansion of Tehran during two decades, 1960s, and 1970s, and complexity of its problems justified the necessity of planning and supervision of its development. In 1968, first comprehensive plan was prepared. In 1973, an organization was established to monitor and supervise Tehran's expansion. After revolution, all the regulations issued to monitor Tehran's development were considered not credible and growth continued in all directions. 


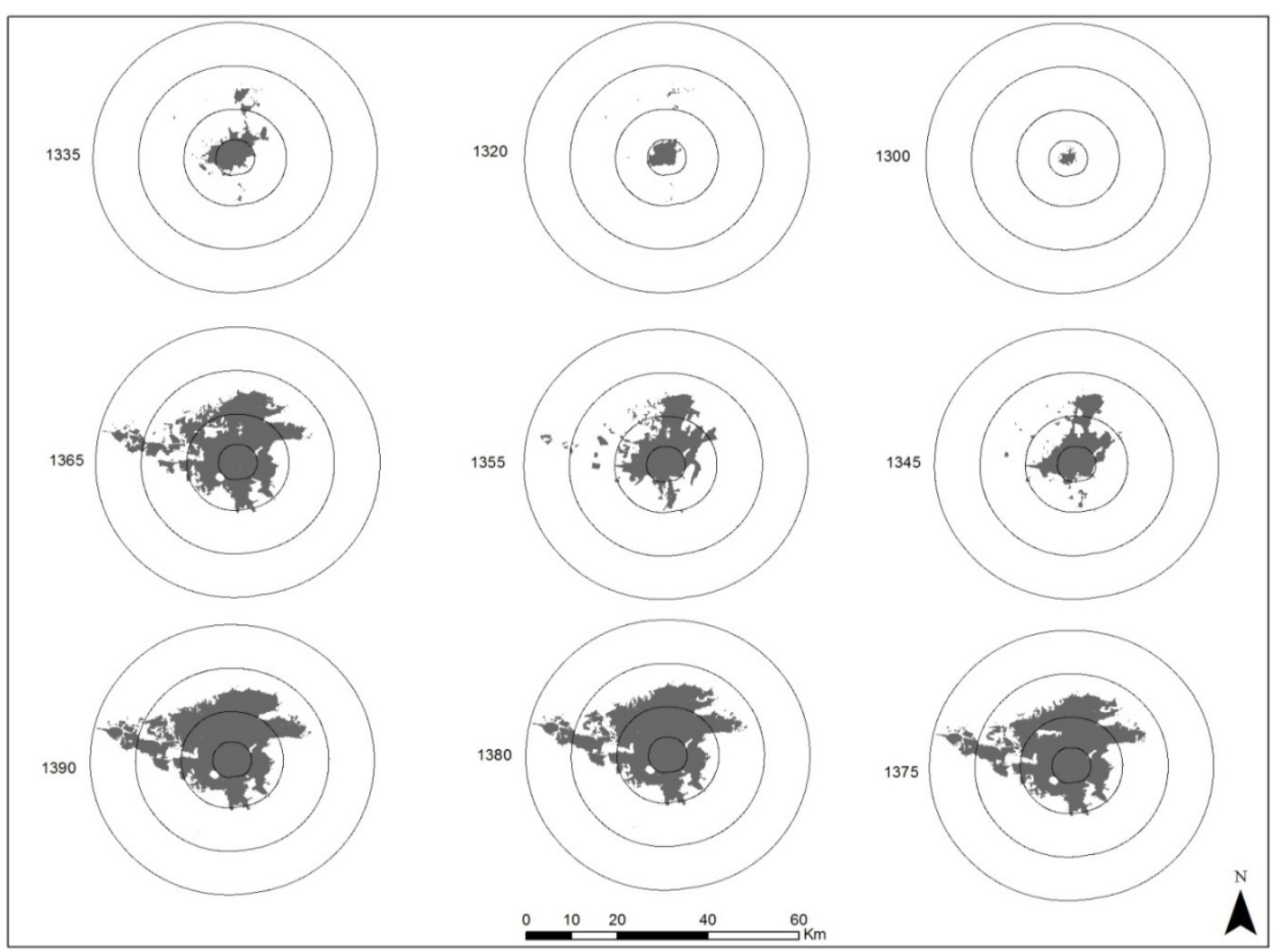

Figure 1. Tehran's urban growth 1921-2011

Tehran's physical growth maps were developed for different time periods using historical maps and Landsat satellite images $(\mathrm{ETM}+, \mathrm{TM})$.

Spatial-temporal patterns of Tehran's growth were analyzed using spatial metrics for the time period 1921-2011. Metrics were selected can the basis of literature review (Dietza et al., 2005; Augilera, 2011; Jain et al., 2011; Herold et al., 2003; Herold et al., 2005; Seto \& Fragkias, 2005). Metrics were calculated using "Fragstats" software. Metrics describe four dimensions: absolute size, relative size, complexity of urban form and spatial distribution of patches. To measure absolute size, two metrics were used: (1) total urban land area, (2) Number of patches. As urban growth occurs, total urban area continually increases due to the highly non-reversible nature of urbanization. The number of urban patches metric is a measure of discrete urban areas in the landscape and is expected to increase during periods of rapid urban nuclei development, but may decrease if urban areas expand and merge into continuous urban fabric (Seto \& Fragkias, 2005).

Relative size was measured using the mean patch size. The mean urban patch size is a function of the number of urban patches and the size of each urban area, and can either increase or decrease through time. Decreasing values of mean urban patch size implies that new urban centers are growing faster than existing urban areas. That is, urban growth occurs more as a process of new and multiple urban nuclei formation than of envelopment or annexation (Seto \& Fragkias, 2005).

The area-weighted mean patch fractal dimension (AWMPFD) metric describes the degree to which the shape of an urban area is irregular or complex. The more irregular the shape of the urban area, the higher the value of the fractal dimension. Values range between 1 and 2 with values closer to 1 indicating areas with relatively simple shapes such as squares or circles. Values that approach 2 represent complex and irregular shapes. The area-weighted mean patch fractal dimension is hypothesized to increase during the early periods of urban land-use change when new urban nuclei and expansion of existing urban space creates irregularly shaped landscape patterns. This metric is expected to decline as urban form becomes more regular (Seto \& Fragkias, 2005).

To describe the spatial distribution of urban patches, two metrics were used: Euclidian mean nearest neighbor distance and contiguity. With the development of new patches, value of Euclidian mean nearest neighbor distance increases; then, with more continuity and joining of the patches, the values of this metric decrease. The 
value of 0 for second metric, continuity shows that no urban pixel is adjacent with other urban pixels. Value of 1 show that all pixels with urban land use is adjacent to each other (Table 1).

Table 1. Expected landscape pattern metrics as a function of urban land-use change

\begin{tabular}{|c|c|c|c|c|c|c|c|c|c|}
\hline \multirow{2}{*}{ Variable } & \multirow{2}{*}{ Description } & \multicolumn{8}{|c|}{ Urban land-use change time periods } \\
\hline & & 1 & 2 & 3 & $\ldots$ & $\ldots$ & 8 & 9 & 10 \\
\hline UA & Total Urban Area & + & + & + & & & + & + & + \\
\hline AWMPFD & Area- Weighted Mean patch Fractal Dimension & + & + & + & & & + & + & + \\
\hline NUMP & Number of Urban Patches & + & + & + & & & + & - & - \\
\hline MPS & Mean Urban Patch Size & \pm & \pm & \pm & & & \pm & \pm & \pm \\
\hline ENN-MN & Euclidian Mean Nearest Neighbor Distance & + & + & + & & & + & - & - \\
\hline CONTAG & Contiguity & - & - & - & & & - & + & + \\
\hline
\end{tabular}

Reference: Seto and Fragkias (2005).

In this article, spatial metrics were calculated for years of 1921, 1941, 1956, 1966, 1976, 1986, 1996, 2001, 2006, and 2011 in four zones with distance: 0-3, 3-10, 10-20, 20-30 Km from city center. Distances for rings were chosen on the basis of literature review.

\section{Results}

Current study looked at the spatial- temporal patterns of urban growth in Tehran city at two levels. First, Tehran's urban growth patterns as a whole. Second, Tehran's growth at concentric zones level.

\subsection{Tehran's Urban Growth Pattern as a Whole}

Tehran's urban land area has been constantly increasing from 1921-2011 and Urban growth curve has always been ascending. Its grade was steep during 1921 to 1976. But the grade is steeper for the years 1976-1986 which shows very rapid urban growth in this time period. After 1986, urban growth curve shows less steep grade and gradually has turned into almost flat shape. It shows the stable urban growth rate. But population increase continues to grow.

On the contrary urban growth rate curve shows decreasing trend. Urban growth rate curve had decreasing grade between 1921-1976. Between, 1976-1986, growth rate had ascending shape. From 1986 to 1996, growth rate has been decreasing and since 1996, the curve is almost flat.

Diagram showing the number of patches for the years 1921-2011, is an ascending curve. During 1921-1956 with the development of new patches in north and south of Tehran city, number of patches increases very rapidly. Between, 1956-1966, the number of patches decreases. The reason is the continuation of urbanization and patches joining each other. During 1966-2001 Number of patches have been increasing, but since 1996, the rate of increase had been very slow and in some instances constant. New patches have been mostly developed in northwest and southwest of Tehran during this period.

During presenting AWMPFD slows two conditions. The value of this metric has reduced 1921-1941, between 1941-1986, the value of this measure has increased which means irregularity in the form of this urban area. Since 1986 the value of this metric has reduced and since 2001, it has been stable which means more regularity in urban form.

Mean patch size presents the relation between patches land area and their number. The value of this metric has been increasing between 1921-1966. The grade has steep slope. Since 1966, it has decreasing trend and flat (stable) form since 2006. The fluctuation is related to the expansion of central core and annexation of patches surrounding the central core until 1996. Since 1966, there are more development of the new patches.

The values related to contiguity of patches shows almost stable trend between 1921-1976. But it has very steep reducing slope between 1976-1996. Since 1996, again it shows stable trend. Results of analysis of this metric shows growth and expansion of central core up to 1976 and then rapid formation of new patches until 1996 and then it shows reduction of growth rate.

Diagram related to the Euclidian mean nearest neighbor distance metric, had ascending slope between 
1921-1941. It shows the formation of new patches in north and south of Tehran. Descending values between 1941-1956 show the connection and attaching of patches in north to the patches in the central of city core. The value of this metric increase between 1956-1966, because of the formation of new urban patches in northwest of Tehran and then the empty spaces between built up areas are filled, and patches in the south are joined and are attached to the central city core.

\subsection{Tehran's Growth Patterns Within Each Concentric Zone}

To analyze the spatial-temporal changes of urban growth, with increasing distance from the city center, concentric zones where drawn. Within $0-3 \mathrm{~km}$ from city center, a growing trend is observed with the passage of time. In 1921, only 8.3 hectares of this zone's land area were built up. In 1941, the built up area reached 28.27 hectares with 240 percent growth rate. "Between" 1941 to 1956, the growth rate within the zone reduced to 53.08 percent and urban built up area reached to 43.29 hectares. Build up areas with reducing growth rate reached to 51.89 hectares in 1966, 53.88 in 1976, and to 55.56 hectares in 1986. After 1986, the urban growth rate reaches to 0 (Figure 3).

Spatial - temporal changes in second zone, 3-10 km from city core shows rapid growth since 1956 . The urban built up before 1941 was less than one hectare. In 1956, with the growth rate of 97.8 percent, it reached to more than 32 hectares. In 1966, it reached to 83.5 hectares, in 1976, to 138.7, and in 1986, to 228.7. Between 1986-1996, the growth rate was reduced to 6.47. The urban built up area in the second zone reached 244.5 hectares (Figure 3).

Changes in third zone with 10-20 km distance from city center starts from 1941. The urban built up area was 2.5 hectares in 1941. In 1956, the growth rate was 77.3 percent, 10.7 hectares built up areas, the built up area in zone three were 29.3 hectares in 1966, 39.5 in 1976, 72.5 in 1986 and 94.6 in 1996. Since 1996, the growth rate started to decrease. The built up area in zone three reached to 100 hectares with a growth rate of 23.3 percent between 1996-2006. Then, the growth rate was stable.

Spatial - temporal changes in zone four is more limited compared with other zones. The beginning of the urban growth in this zone was 1976. The built up area was 3.5 hectares. It reached to 19.4 hectares in 1986 . The built up area reached 26.8 hectares in 2011.

Numbers of patches, in each zone, are presented in Figure (3). Numbers of patches were 11 in 1921. In 1941, there was only one patch as a result of coalescence of 11 patches. In 1956, 5 new patches were developed and they were attached and made 1 patch in 1976 (Figure 3). In zone 2, which is 3-10 km far from the city core, number of patches increase from one in 1921 to 42 patches in 1956. Then, with the coalescence of patches, there were 12 patches in 1986. In 2006, there were 32 patches (Figure 3). In zone 3, 10-20 km from city center, the number of patches increased from 17 in 1941 to 50 in 1996. With the convergence of patches, there were 45 patches in 2011 (Figure 3). In zone 4, 20-30 km from city center, patches started to develop in 1976, with 5 patches and it reached to 22 in 2011 (Figure 3).

The metric value of AWMPFD in zone 1, 0-3 km far from city center has a mild decreasing value. In 1921, it was 1.09 and it reached to 1.02 in 1986. During this time period, patches have converted to more regular forms. In zone 2, 3-10 km, the AWMPFD metric had increasing value. After 1986, the metric value decreases. In 2001, it reached the constant value of 1.14. In zone 3,10-20 km from city core, the value was 1.09 in 1941. It reached to 1.07 in 1956-1966. Then in 1976-1986 it increased to 1.09 , and 1.14. In 1996, there was a minor reduction, 1.12. Again, in 2001 and 2006, it increased to 1.13 and 1.4 and then constant value (Figure 3).

The reduction in mean patch size shows that new patches have been developed. The increase in mean patch size shows the expansion of existing of patches. In the first zone, 0-3 km far from the city center: In 1921, the mean patch size was less than $1 \mathrm{~km}^{2}$. With the joining of patches, mean patch size reached $28 \mathrm{~km}^{2}$ in 1941 . With the development of new patches, the mean patch size had considerable reduction, $8.5 \mathrm{~km}^{2}$. But this metric continued its increasing value. In 1986, mean patch size reached to $55 \mathrm{~km}$ square. Later, the value of this metric remained constant. In second zone, 3-10 km from the city center, mean patch value was $19 \mathrm{~km}^{2}$ in 1986 . With the development of new patches, the mean patch size was reduced to $7.8 \mathrm{~km}^{2}$ in 2006 . Mean patch size in their zone, $10-20 \mathrm{~km}$ from city center, compared with the two closer zones is lower. The reason is urban sprawl event and rapid development of new urban patches in this zone. In the fourth zone, 20-30 km distance from city center, first the increase in the value of mean patch size is observed, and after 2001, with the development of new urban patches, the value of this metric declined (Figure 3 ). 

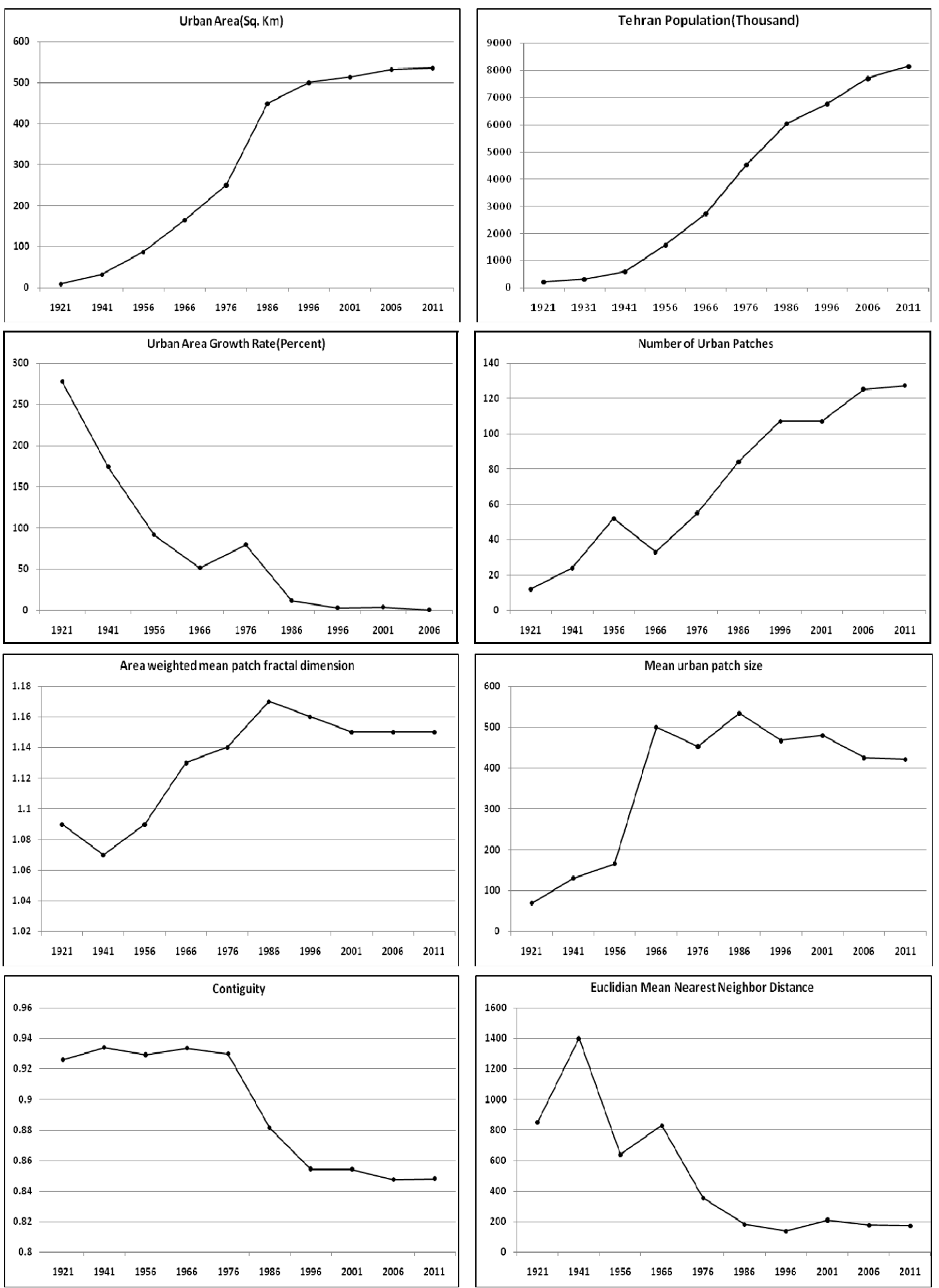

Figure 2. Spatial - temporal changes of urban growth patterns in Tehran megapole

The value of contiguity metric was 0.99 between 1921-1941. It had considerable decline between 1956-1966, 0.7 after 1966, the value of this metric had increasing trend and reaches to a stable situation in 1976. In second zone the contiguity metric shows an increasing value between 1921-1956. Then, it showed decreasing trend until 1986 and then it shows a stable value. This metric had decreasing value until 1976 and then increasing value in 1986 and stable value after this time. In fourth zone, changes in the value of contiguity metric are not 
considerable. The value of this metric show stable trend until 2001, and then it shows minor reduction (Figure 3 ).

The Euclidian mean nearest neighbor distance metric is another indicator for describing the spatial arrangement of urban patches. The value of this metric was 205 meters in 1921. With the coalescence of patches in 1941, and development of joined patches, this value reaches zero. In 1956, with the emergence of new patches, the value of this metric was 107 meters. Between 1956-1976, this value had decreasing trend. In the second zone, the highest value for this metric is related to 1941 , when, mean geometry distance to nearest neighbor was more than 2200 meters, after 1941, the value of this metric had decreasing value. The situation is also the same, with a reducing value for this metric; it shows the development of new patches and urban sprawl at the edges (Figure 3).
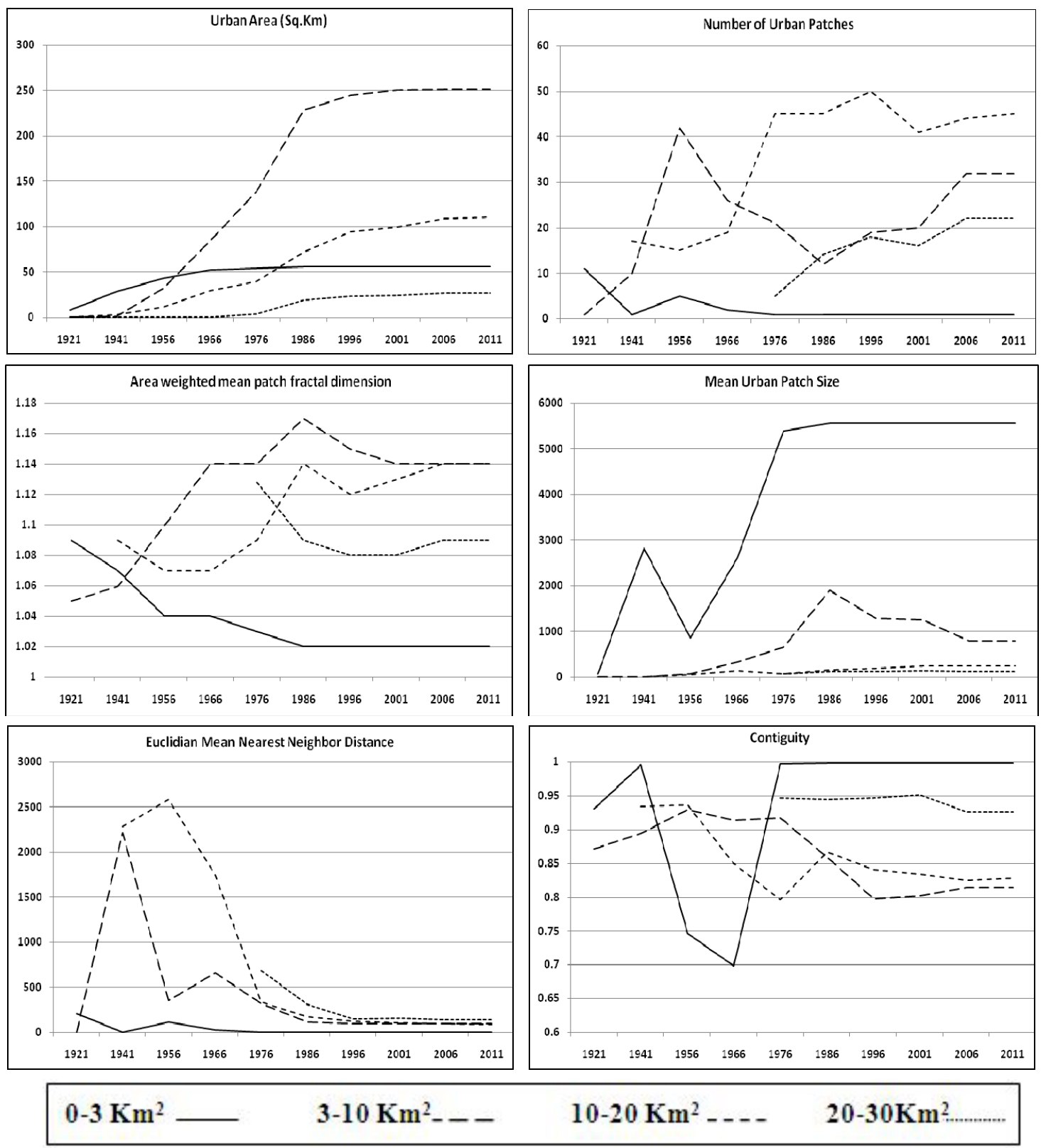

Figure 3. Tehran's growth patterns within each concentric zone

\section{Discussion}

The spatial - temporal analysis of metric in Tehran megapole prove a number of the deductive generalizations. First, urban growth in Tehran can be divided into three time period. First period (1921-1976), urban physical expansion was rapid, but urban growth rate was consistent. Most important reasons for urban growth are 
industrial investment, concentration of political and economic activities in Tehran and also rural-urban migration Second period, 1976-1986, showed very rapid urban growth in Tehran. The important reasons are Islamic revolution, lack of implementing and supervision of the master plan. Third period 1986-2011, urban growth rate declines and then reaches relatively stable condition. Reasons are socio-economic and environmental problems of Tehran city. Preparing and approving various plans to control Tehran's physical growth and transferring the growth to Tehran's surrounding area.

Second point, is that Tehran urban growth pattern shows the process of urban growth in three stages: (1) development of city core, (2) diffusion and (3) coalescence. Results of these spatial metrics show this process. For example, number of patches shows its increasing value until 1996 and then a stable trend. It is expected that with more infill development and attachment of individual patches to each other to more convergence and coalescence of patches. The value of AWMPFD shows that until 1986, the form of patches have been more irregular. Since 1986, with the attachment of patches, more regularity is observed. The values related to geometric distance of nearest neighbor were high between 1941-1966 and then decreasing values are observed as a result of the attachment of patches to each other.

Third point is the approval of tidal wave urban growth pattern for Tehran city. With the decrease of urban growth in one zone in a concentric pattern, the tidal wave pattern of urban growth is observed in the next zone. The high peak of urban growth moves like a wave to outer zones.

Forth point, is that urban growth pattern in different zones flows the same pattern happening for the whole city: formation of city core, dispersion and coalescence. Values extracted for the following metrics: number of patches, fractural dimension, mean size, contiguity and mean geometric distance to nearest neighbor shows that in each zone, the same pattern is happening in different time periods. For example, AWMPFD shows an increasing trend and increasing and then decreasing trend in all zones with the passage of time. This shows dispersion of individual patches, expansion of central core and then coalescence of patches with the passage of time.

Fifth point is that comparison of the results of this study with other studies (Li et al., 2006; Zhang et al., 2001; Yu et al., 2007; Yu et al., 2006; Yang et al., 2003; Xu et al., 2007; Luck et al., 2002; Ji et al., 2006; Aguilera, 2011) show that urban growth process in majority of cities follows the tidal wave pattern, but this process is also affected by (social, topography, transportation network, socio-economic condition), and creates different pattern in different countries. For example, in case of Tehran city, existence of the mountains in the northern part of Tehran prevents growth in that area.

In general, determining patterns and processes of urban growth can provide better understanding of urban growth and quantifying urban growth by using spatial metrics has an important role.

\section{References}

Aguilera, F., Valenzuela, L. M., \& Botequilha-Leitão, A. (2011). Landscape metrics in the analysis of urban land use patterns: A case study in a Spanish metropolitan area. Landscape and Urban Planning, 99(3), 226-238. http://dx.doi.org/10.1016/j.landurbplan.2010.10.004

Bayoh, I., Irwin, E. G., \& Haab, T. (2002). Flight from Blight vs. Natural Evolution: Determinants of Household Residential Location Choice and Suburbanization. In 2002 Annual meeting, July 28-31, Long Beach, CA (No. 19668). American Agricultural Economics Association (New Name 2008: Agricultural and Applied Economics Association).

Bourne, L. S. (1971). Internal Structure of the City: reading on space and environment. Oxford university press.

Dietzel, C., Herold, M., Hemphill, J. J., \& Clarke, K. C. (2005). Spatio - temporal dynamics in California's Central Valley: Empirical links to urban theory. International Journal of Geographical Information Science, 19(2), 175-195. http://dx.doi.org/10.1080/13658810410001713407

Forman, R. T. T. (2008). Urban Regions: Ecology and Planning Beyond the City. Harvard University. http://dx.doi.org/10.1017/CBO9780511754982

Gayda, S., Boon, F., Schaillée, N., Batty, M., Besussi, E., Chin, N., ... Dormois, R. (2003, April). The SCATTER project-sprawling cities and transport: from evaluation to recommendations. In European Transport Conference.

Herold, M., Couclelis, H., \& Clarke, K. C. (2005). The role of spatial metrics in the analysis and modeling of urban land use change. Computers, Environment and Urban Systems, 29(4), 369-399. http://dx.doi.org/10.1016/j.compenvurbsys.2003.12.001

Herold, M., Goldstein, N., \& Clarke, K. C. (2003). The spatio-temporal form of urban growth: measurement, 
analysis and modeling. Remote Sensing of Environment, 86(3), 286-302. http://dx.doi.org/10.1016/S0034-4257(03)00075-0

Jain, S., Kohli, D., Rao, R. M., \& Bijker, W. (2011). Spatial Metrics to Analyse the Impact of Regional Factors on Pattern of Urbanisation in Gurgaon, India. Journal of the Indian Society of Remote Sensing, 39(2), 203-212. http://dx.doi.org/10.1007/s12524-011-0088-0

Ji, W., Ma, J., Twibell, R. W., \& Underhill, K. (2006). Characterizing urban sprawl using multi-stage remote sensing images and landscape metrics. Computers, Environment and Urban Systems, 30(6), 861-879. http://dx.doi.org/10.1016/j.compenvurbsys.2005.09.002

Kong, F., Yin, H., Nakagoshi, N., \& James, P. (2012). Simulating urban growth processes incorporating a potential model with spatial metrics. Ecological Indicators, 20, 82-91. http://dx.doi.org/10.1016/j.ecolind.2012.02.003

Ladd, H. (1998). Effects of taxes on economic activity. In H. Ladd (Ed.), Local government tax and land use policies in the United States: Understanding the links, 82-101.

Lewis, P. G. (2001). Retail politics: Local sales taxes and the fiscalization of land use. Economic Development Quarterly, 15(1), 21-35. http://dx.doi.org/10.1177/089124240101500102

Li, X., \& Yeh, A. G. O. (2004). Analyzing spatial restructuring of land use patterns in a fast growing region using remote sensing and GIS. Landscape and Urban planning, 69(4), 335-354. http://dx.doi.org/10.1016/j.landurbplan.2003.10.033

Luck, M., \& Wu, J. (2002). A gradient analysis of urban landscape pattern: a case study from the Phoenix metropolitan region, Arizona, USA. Landscape ecology, 17(4), 327-339. http://dx.doi.org/10.1023/A:1020512723753

Mahdizade, J. (2002). City and history (First part). Jostarhaye shahrsazi, 2, 13-22.

Mahdizade, J. (2002). City and history (Second part). Jostarhaye shahrsazi, 3, 16-26.

Mahdizade, J. (2002). City and history (Third part). Jostarhaye shahrsazi, 4, 37-43.

Mahdizade, J. (2002). City and history (Forth part). Jostarhaye shahrsazi, 5, 34-41.

Mieszkowski, P., \& Mills, E. S. (1993). The causes of metropolitan suburbanization. The Journal of Economic Perspectives, 7(3), 135-147. http://dx.doi.org/10.1257/jep.7.3.135

Seto, K. C., \& Fragkias, M. (2005). Quantifying spatiotemporal patterns of urban land-use change in four cities of China with timer series landscape metrics. Landscape Ecology, 20, 871-888. http://dx.doi.org/10.1007/s10980-005-5238-8

Wu, J. G. (2008). Making the case for landscape ecology: an effective approach to urban sustainability. Landscape and Ecology, 27, 41-50.

Wu, J. G., Jenerette, G. D., Buyantuyev, A., \& Redman, C. L. (2010). Quantifying spatiotemporal patterns of urbanization: The case of the two fastest growing metropolitan regions in the United States. Ecological Complexity.

Xu, C., Liu, M., Zhang, C., An, S., Yu, W., \& Chen, J. M. (2007). The spatiotemporal dynamics of rapid urban growth in the Nanjing metropolitan region of China. Landscape ecology, 22(6), 925-937. http://dx.doi.org/10.1007/s10980-007-9079-5

Yang, X., \& Lo, C. P. (2003). Modelling urban growth and landscape changes in the Atlanta metropolitan area. International Journal of Geographical Information Science, 17(5), 463-488. http://dx.doi.org/10.1080/1365881031000086965

Yu, X., \& Ng, C. (2006). An integrated evaluation of landscape change using remote sensing and landscape metrics: a case study of Panyu, Guangzhou. International Journal of Remote Sensing, 27(6), 1075-1092. http://dx.doi.org/10.1080/01431160500377162

Yu, X. J., \& Ng, C. N. (2007). Spatial and temporal dynamics of urban sprawl along two urban-rural transects: A case study of Guangzhou, China. Landscape and Urban Planning, 79(1), 96-109. http://dx.doi.org/10.1016/j.landurbplan.2006.03.008

Zhang, Q., Ban, Y., Liu, J., \& Hu, Y. (2011). Simulation and analysis of urban growth scenarios for the Greater Shanghai Area, China. Computers, Environment and Urban Systems, 35(2), 126-139. http://dx.doi.org/10.1016/j.compenvurbsys.2010.12.002 


\section{Copyrights}

Copyright for this article is retained by the author(s), with first publication rights granted to the journal.

This is an open-access article distributed under the terms and conditions of the Creative Commons Attribution license (http://creativecommons.org/licenses/by/3.0/). 